\title{
Alterações e Manutenções: leituras sobre a geometria como saber escolar
}

SILVA, M.C.L. da; VALENTE, W.R. (Orgs.). A geometria nos primeiros anos escolares: história e perspectivas atuais. Campinas: Papirus, 2014. 141 p.

Dentre os historiadores que abraçam concepções contemporâneas sobre história, três princípios já enunciados em Bloch parecem indiscutíveis: aceitar que a origem de uma narrativa historiográfica é sempre arbitrada, atendendo a uma disposição do narrador; concordar que a origem não justifica a permanência; entender que as circunstâncias humanas do passado - que a história pretende prender num emaranhado de significados entrelaçados são analisadas à luz do presente, numa dinâmica de manutenções e alterações que não ocorrem linearmente nem são guiadas pela ideia de progresso.

O recente livro organizado por Maria Célia Leme da Silva e Wagner Rodrigues Valente, A geometria nos primeiros anos escolares: história e perspectivas atuais, nos permite um exercício sobre essas concepções que, segundo penso, seria importante a todos os que escrevem história e, mais particularmente, história da Educação Matemática. Seu tema: como, no ensino primário brasileiro, se constitui e se mantém - em meio a uma dinâmica intensa de transformações - uma geometria escolar.

Ainda que o livro - como enunciam explicitamente tanto o prefácio, de Ana Maria Kaleff, quanto os próprios autores, na Introdução - tenha como público-alvo o professor que ensina Matemática para os anos iniciais, segundo os autores; e/ou os cursos de formação de professores, segundo Kaleff, o pesquisador do campo da História da Educação Matemática, não apenas por ser, também, professor que ensina Matemática - pode aproveitá-lo do mesmo modo, dada a diversidade de fontes nele disponibilizadas, os exercícios de análise sobre essas fontes e as possibilidades de problematização que ele abre, seja em relação à prática de escrever história ou às práticas didáticas relativas à Matemática.

\footnotetext{
* Docente do Departamento de Matemática da Faculdade de Ciências da UNESP de Bauru e dos Programas de Pós-graduação em Educação Matemática (UNESP-Rio Claro) e Educação para a Ciência (UNESP-Bauru). Endereço para correspondência: Departamento de Matemática. Avenida Luiz E. C. Coube, s/n. 17033-360. Bauru-SP. E-mail: vgarnica@fc.unesp.br.
} 
Deve-se ressaltar, entretanto, que nem todos os quatro capítulos do texto são marcados pela mesma disposição historiográfica, viés acentuado nos três capítulos iniciais, que tecem como que um fio sequencial desde os primórdios do ensino de geometria nos anos iniciais (este o título do primeiro capítulo, que já arbitra aquela origem da narrativa da qual falávamos), passando pelo Ensino de Geometria nos Grupos Escolares, segundo capítulo, escrito por Silva e Valente, até chegar à perspectiva do Movimento Matemática Moderna, terceiro capítulo, escrito por Pinto e Valente. O quarto capítulo, redigido por Lima e Carvalho, - no qual há um diálogo mais direto com o professor que ensina Matemática acerca de conceitos geométricos e de formas possíveis de tratá-los em sala de aula, mas que, talvez por priorizar esse diálogo no presente não esteja entrecortado por uma perspectiva, digamos, histórica, nem teça relações com os capítulos anteriores, como fazem os três primeiros textos da coletânea - talvez esteja representado, no subtítulo da obra, pela expressão perspectivas atuais, ao passo que os demais capítulos respondem ao termo história, que consta do mesmo subtítulo. A conclusão, elaborada por Wagner Rodrigues Valente, explica a presença desse quarto capítulo, advogando por um vínculo entre ele e os capítulos anteriores: posto que coube aos primeiros capítulos analisar como a geometria se constitui em saber escolar para a escola primária brasileira, em meio a transformações e interferências dos mais variados matizes, seria necessário analisar, no presente,

\section{[...] as referências tidas como importantes, tendo em vista a geometria escolar para o ensino fundamental, com destaque para os anos iniciais, em relação a como e ao que abordar nos primeiros contatos com a geometria, E, neste caso [do quarto capítulo], os temas tratados, conteúdos presentes para serem ensinados nos primeiros anos escolares, foram considerados de um ponto de vista mais avançado, sistematizados e com dose maior de rigor matemático (VALENTE, 2014, p. 129).}

Segundo Silva e Valente, as primeiras discussões sobre o ensino de Geometria nos cursos primários brasileiros pode ser encontrada em texto de Martim Francisco d'Andrada Memórias sobre a reforma de estudos da Capitania de São Paulo -, que defende proposta similar - uma quase tradução - àquela do Cinco memórias sobre a instrução pública, de Condorcet (2008) "o conteúdo desse ensino deve articular-se com a prática da agrimensura: um ensino de geometria para a prática, uma geometria prática para a primeira etapa da escolarização". Desejando arbitrar um momento anterior à narrativa sobre a constituição, no Brasil, de um saber escolar relativo à geometria, o leitor poderia procurar aprofundar suas leituras acerca da posição do Marquês de Condorcet e dos Iluministas acerca da Instrução pública e, nela, das propostas para o ensino de geometria. Silva e Valente, entretanto, escrevendo para o professor que ensina matemática, sensatamente dão ao leitor apenas 
algumas indicações gerais acerca da posição de Condorcet sobre o assunto, e seguem em seu texto para abordar o primeiro fórum de discussão educacional instalado a partir da Independência: os debates parlamentares sobre a instrução popular.

O projeto da Casa Legislativa fixa, não sem controvérsias, que nas escolas primárias, “os professores ensinarão a ler, escrever, as quatro operações da aritmética, prática dos quebrados, decimais e proporções, as noções mais gerais de geometria prática, a gramática da língua nacional" (grifo dos autores). Sai vencedora dos debates, portanto, a linha dos parlamentares que, de alguma forma, abraçam a proposta de Martim Francisco, incluindo, em decorrência, a geometria dentre os saberes a serem ensinados na escola primária. Além disso, abraçam também, de alguma forma, aquela proposta condorcetiana que enfatiza o ensino dessa geometria prática. Interessante notar que se trata de um ponto de vista defendido pelo intelectual francês que, antes do período revolucionário, adepto das posições de Rousseau, Locke e Condillac, defendia o preceptorado, a instrução privada, para a educação da infância, e para o qual, apenas anos mais tarde, "a instrução pública passa a se configurar [...] como uma resposta direta à contingência histórica, como alternativa anticlerical" (GOMES, 2008, p. 226). Interessante, também, notar que o plano de Concorcet - o Informe sobre a organização da instrução pública, baseado nas Cinco Memórias -, sequer votado pela Assembléia Legislativa do governo revolucionário, esteve na pauta de vários outros planos posteriores para a instrução pública da França, até fixar-se em solo brasileiro, na Lei de 15 de Outubro de 1827, marco historiográfico da educação nacional.

A lei de 1827 cria a escola primária em todas as cidades e vilas e aposta na adoção do método mútuo, do que decorre a publicação de livros que pudessem ajudar os mestres na tarefa que agora era deles exigida. Nesse cenário, surge a obra de Holanda Cavalcanti de Albuquerque, uma tradução/adaptação do Desenho Linear e Agrimensura, para todas as escolas primárias, qualquer que seja o modo de instrução que seja seguido, de 1819, referência para o ensino em Portugal e no Brasil, e cujo autor, Louis-Benjamin Francoeur, é pioneiro em sistematizar os conteúdos de desenho para as escolas de ensino mútuo. Mas, segundo Silva e Valente (p. 31)

[...] a análise do livro de Holanda Cavalcanti [...] mostra que a geometria será prática se os alunos forem levados a trabalhar com as figuras geométricas. [...] associar a esse ensino de geometria a agrimensura, a medição de terrenos, como é a intenção inicial de Condorcet, parece ter sido deixado de lado. [...]. A representação do caráter prático migra, ao que parece, de atividades rurais - como a medição de terrenos - para as profissões que têm lugar nas vilas e cidades francesas ao tempo da escrita da obra de Francoeur. E mais: a forma prática dessa geometria deverá ser demonstrada no âmbito escolar: a atividade dos alunos com o desenho das formas geométricas. Não mais o campo, o terreno, como lugar da ação dos alunos é prova 
do caráter prático. Assim, nesses tempos iniciais, logo ficam à mostra as transformações de significado da geometria prática: nasce, desse modo, uma geometria escolar.

A cadeia de transformações pela qual passa a geometria ensinada nas escolas primárias leva, portanto, de uma geometria prática (essencialmente vinculada à agrimensura, como propunha Condorcet) ao desenho linear (uma prática relativa ao aprendizado da construção de linhas à mão livre. Uma prática de adestramento do olhar, rumo à precisão dos traçados) e, deste, à abordagem ${ }^{1}$ que aponta como saberes a serem ensinados "a caracterização e a nomenclatura dos objetos geométricos. [...] Às aritméticas, agrega-se a geometria considerada mínima para o curso primário: os seus primeiros elementos, as primeiras definições" (SILVA; VALENTE, 2014, p. 38-9).

Pode-se notar, nos parágrafos anteriores (que nada mais são que uma síntese tosca das detalhadas análises realizadas no primeiro capítulo do livro aqui resenhado) esse processo de apropriação e transformação de ideias $^{2}$ que servem de exemplo àquela não-linearidade a que nos referimos no início deste artigo e que cabe à historiografia estudar: por mais que a elaboração textual teime em exigir uma linearidade na apresentação, as ideias apresentadas explicitam o tortuoso caminho para que uma determinada apreensão se estabeleça, criando vínculos e impondo-se como referência, entre permanências e alterações. Trata-se, percebe-se, de uma defesa constante da prática como aliada à geometria escolar, ainda que essa prática possa ser (e efetivamente seja) lida de modo diferente com o correr do tempo. Os interessados em historiografia - e, especificamente, os interessados ou especialistas em História da

\footnotetext{
${ }^{1}$ O representante desse viés é o Manual Enciclopédico para uso das escolas de instrução primária, do português Emílio Achilles Monteverde, que parece fazer escola para outros livros (como, por exemplo, os livros do brasileiro Souza Lobo).

${ }^{2}$ Pode-se notar, por exemplo, que em seu Reflexões e notas sobre a educação, do final do século XVIII, Condorcet já explicita um programa de estudos, estabelecendo a ordem a ser seguida no ensino. A primeira das ciências a ser estudada seria a aritmética, seguida da geometria ("explicar-se-lhe-iam [às crianças] as proporções sobre as linhas, sobre as superfícies, sobre os sólidos que se podem entender sem a teoria das proporções" (GOMES, 2008, p.222). Lacroix, um contemporâneo muito próximo de Condorcet, em sua obra autobiográfica sobre a instrução pública francesa no século XVIII, confessando sua ignorância acerca do ensino das crianças na primeira idade, mas não abrindo mão de opinar sobre isso, sentencia que seria conveniente, quanto às primeiras instruções dadas na infância, "empregar tanto quanto possível o testemunho dos sentidos" (LACROIX, 2013, p.147), no que não há discordância com o Marquês. Em seguida, porém, complementa: "A Geometria é, talvez, de todas as partes da Matemática, aquela que se deve aprender primeiro. Ela me parece muito adequada para atrair as crianças, desde que seja apresentada principalmente com relação às suas aplicações, tanto teóricas quanto práticas. As operações de traçado e de medição certamente agradarão aos alunos e os conduzirão, em seguida, como que pela mão, ao raciocínio. Aqui [neste meu livro] não é lugar para desenvolver essas ideias, que estão expostas de maneira tão verdadeira quanto eloquente no final do segundo livro do Emílio". Para Lacroix, o costume de ensinar primeiro a ciência dos números - a Aritmética - prevaleceu apenas por serem mais frequentes as aplicações do "cálculo numérico" (LACROIX, 2013, p. 244-5).
} 
Educação Matemática que, reiterando, não são (mas bem poderiam ser) o público-alvo do livro organizado por Silva e Valente - podem, a partir desse livro, destrinchar o emaranhado de linhas que conduzem ora a um resultado, ora a outro; que partem de uma mesma compreensão para criar diferentes versões, incluindo aquela que, num movimento homeopático e subversivo, tornar-se-á, de alguma forma, a versão hegemônica ou preponderante. Por outro lado, mesmo para o público-alvo do livro - os professores que ensinam Matemática - talvez fosse interessante problematizar - ou aventar perspectivas possíveis e plausíveis - sobre o que leva uma proposta de teor nitidamente prático - o ensino de geometria vinculado à agrimensura - deformar-se a ponto de se aproximar de uma apreensão mais teórica, mais elementar (no sentido euclidiano) ${ }^{3}$, como aquela veiculada nos manuais escolares de Souza Lobo (publicados na segunda metade do século XIX mas com edições até os anos de 1930, estudados em Silva e Valente). Uma dessas possibilidades, parece-me, traz à tona uma faceta da comunidade à qual o livro de Silva e Valente se dirige: trata-se da formação de professores. Se não, vejamos: mesmo Condorcet, que não era favorável aos livros de elementos para as crianças, recomendava aos professores dessas crianças as obras de Aritmética e Álgebra do padre Bossut e uma tradução francesa dos Elementos de Euclides (GOMES, 2008). Sabe-se que, passado um século da época de Condorcet, já na Inglaterra Vitoriana, o surgimento de manuais de Geometria para o ensino, alternativos ao de Euclides, causou vasta polêmica envolvendo a comunidade de matemáticos e educadores (MONTOITO, 2013). Nessa polêmica envolve-se, por exemplo, Lewis Carroll, cuja obra Euclides e seus rivais modernos, de 1879, é uma veemente defesa da manutenção dos Elementos como texto-base nas escolas inglesas. Não é polêmica - de modo geral, e não apenas à luz desses dois exemplos - a permanência da obra de Euclides no pensamento ocidental, seja na filosofia (como uma apreensão ao que seria Matemática) (MONTOITO; GARNICA, 2014), seja como estratégia de ensino para as salas de aula. Formados segundo essas concepções de uma Matemática que só têm sentido na órbita euclidiana ${ }^{4}$, não seria

\footnotetext{
${ }^{3}$ Os tempos revolucionários, na França, marcaram também uma nova apreensão ao adjetivo elementar que, frequentemente, caracterizava os livros de Matemática. Antes desse período, a expressão Elementos de... indicava, mais frequentemente, obras cujo modelo era os Elementos de Euclides, ou seja, obras nas quais da apresentação e discussão de uma série de resultados essenciais a uma certa área decorriam outros resultados, também centrais a essa área. O conjunto dessas proposições essenciais com suas decorrências, ao qual algumas vezes vinculavam-se exemplos, constituía o corpo de uma determinada disciplina, seus elementos (no sentido euclidiano). Ao final do século XVIII, Elementos de... passaram a indicar livros elementares, no sentido mais usual do termo: obras voltadas ao ensino, com os conteúdos básicos de um determinado campo (Aritmética, Álgebra, Geometria etc.).

${ }^{4}$ Opera exatamente nesse sentido a consideração feita por Lacroix ao discutir suas intenções, como autor, em seu Elementos de Geometria: "Se a dificuldade de fazer bons tratados, em qualquer que seja a ciência, é muito
} 
implausível pensar no papel que os autores dos Manuais escolares do passado desempenham ao elaborar suas obras: cuidam de deslizar para a prática didática as abordagens da prática científica segundo a qual eram formados. São, portanto, agenciadores. Esse debate, ainda bastante atual, pode ser levantado a partir da leitura do texto aqui resenhado, e poderia mesmo dele fazer parte, como questionamento explícito das práticas de agenciamento efetivadas por aqueles aos quais esse mesmo texto se destina.

Tratados esses primórdios, são os ventos republicanos e seu modelo específico de organização educacional - os Grupos Escolares - que constituem o pano de fundo do que o leitor encontrará no segundo capítulo. Fundamental para a organização e consolidação do ensino primário, não só no estado de São Paulo onde foram inicialmente criados ao final do século XIX, os Grupos Escolares são parte do esforço republicano, junto à criação de outros símbolos específicos, para a popularização do sistema político então vigente. Sabe-se que, ao contrário do que ocorreu na França, a República brasileira foi uma estratégia das elites, implantada sem a participação popular. Era preciso, pois, extravasar a república para fora do campo da elite, popularizar as potencialidades do novo regime. Para isso, a Educação foi, desde o princípio, chave fundamental. Esse extravasamento "não poderia ser feito por meio do discurso, inacessível a um público com baixo nível de educação formal. Ele teria de ser feito mediante sinais mais universais, de leitura mais fácil, como as imagens, as alegorias, os símbolos, os mitos" (CARVALHO, 2006, p.10). A construção de prédios monumentais foi decorrência dessa necessidade de formar almas, difundindo uma instrução nova, que seguiria uma legislação também nova, diametralmente oposta - pretendiam os republicanos - à da estrutura educacional mantida pelo Império. O método intuitivo, preconizado por Rui Barbosa, que traduzira o livro Lições de Coisas, de Norman Allison Calkins, passava a ser

[...] exaltado como o elemento mais importante dessas novas propostas educacionais", e junto à geometria introduzia-se a taquimetria, "definida por Rui Barbosa como 'concretização da geometria', é o ensino da geometria pela evidência material [...]: é a lição de coisas aplicada à medida das extensões e volumes' (SILVA; VALENTE, 2014, p. 43-4)

O programa de ensino que implantaria essas e outras disposições foi elaborado por “Oscar Thompson, Benedito Tolosa e Antonio Rodrigues Alves [e] oficializado pelo decreto 248 de 26 de junho de 1894." Trata-se de um programa extenso que cobre os quatro anos de

grande, há várias razões que a aumentam ainda mais com relação aos tratados de Geometria: primeiro, a concorrência com um autor consagrado pelas marcas da antiguidade (Euclides), sempre perigosa para um autor moderno, independentemente das razões que este último possa trazer em favor do plano que adota [...]" (LACROIX, 2013, p. 221-2). 
instrução, e no qual o desenho aparece como "apoio importante para a geometria e um auxiliar poderoso à observação". Notam Silva e Valente, porém, que a mobilização do desenho de forma vinculada ao ensino de geometria não é uma novidade no ensino, posto já estar presente em obras didáticas do final do Império (como, por exemplo, no conhecido Desenho Linear ou elementos de geometria prática popular, do Barão de Macaúbas). Tratase, pois, de outra manutenção em meio a uma dinâmica de alterações ${ }^{5}$. Do mesmo modo, mesmo ausente na letra da lei, a expressão Geometria Prática continuava a frequentar o título de manuais como os de Olavo Freire (a primeira obra didática para o ensino primário de geometria em tempos republicanos, publicada em 1894) ${ }^{6}$. Agora, no tempo dos Grupos Escolares, porém, a geometria prática passa a ser caracterizada pelas construções geométricas com régua e compasso, enquanto que o desenho, apartado, torna-se desenho natural, em que se observam e desenham objetos da vida da criança e não mais as figuras geométricas. Se a reforma de 1905 estabelece, além dessa dissociação entre geometria e desenho, uma inversão no desenvolvimento dos conteúdos de ensino da geometria (passa-se a iniciar o ensino, nos primeiro e segundo anos, pelo estudo das figuras espaciais até chegar aos elementos de geometria plana, nos terceiro e quarto anos) que se mantém até meados do século $\mathrm{XX}$, a reforma de 1925 insere no programa uma nova matéria, Formas, para os dois anos iniciais, “configurada como ensino intuitivo, prático, de exploração, manipulação de objetos, sem denominações e construções", reservando aos últimos dois anos a matéria geometria, “caracterizada por definições, propriedades geométricas, construções com utilização de régua e compasso e medidas de áreas e volumes.

Marcas da geometria escolar no ensino primário da época dos Grupos Escolares são, portanto, o novo significado atribuído à expressão Geometria Prática, anunciando a "chegada de instrumentos de construção ao ensino de geometria primário" e "a separação de conteúdos e procedimentos de ensino da geometria e do desenho, num primeiro momento, e de geometria e formas, num segundo período".

Fica-se com a impressão, portanto, a partir das argumentações e análises de Silva e Valente, que, aparentemente, o ensino de geometria não estaria completo, ou não seria adequado, se a abordagem mais intuitiva, mais elementar, mais introdutória, mais prática (qualquer que seja o sentido que se dê a este último termo) não fosse transcendida por uma

\footnotetext{
5 Já na primeira reforma do ensino primário nos Grupos Escolares, ocorrida em 1905, “a proximidade [da geometria] com o desenho não existe mais, as figuras geométricas que eram estudadas e desenhadas como passo inicial no processo de aquisição para desenhos aplicados não constam mais da lista de conteúdos”.

6 Além da obra de Olavo Freire, este segundo capítulo de Silva e Valente considera, também, a coleção (composta de quatro volumes, um para cada ano) Manual do Ensino Primário, de Miguel Milano.
} 
perspectiva mais sistemática, como que iniciando uma abordagem formal e, em decorrência, mais rigorosa (do ponto de vista tradicional em Matemática) dos objetos da geometria. Essa perspectiva, de forma clara, mas vestida com uma roupagem emprestada da Psicologia que se alia às perspectivas matemáticas vistas como modernas e altamente rigorosas - a proposta de Bourbaki - será o tema do terceiro capítulo da coletânea organizada por Silva e Valente: chegamos aos tempos da Matemática Moderna.

O Movimento Matemática Moderna (MMM) foi, como se sabe, tema de um projeto de grande envergadura conduzido pelo GHEMAT, Grupo de Pesquisa de História da Educação Matemática no Brasil, coordenados (pesquisa e grupo) por Valente e do qual participaram ativamente os autores dos três primeiros capítulos do livro aqui resenhado. Boa parte dos estudos em História da Educação Matemática sobre esse tema, principalmente em tempos mais recentes, foi desenvolvida dentro desse projeto e, portanto, essa experiência prévia permite que uma síntese aprofundada desse período e, nele, do MMM, seja feita na produção mais recente de Silva e Valente. A familiaridade dessa experiência prévia, me parece, faz com que temas como o estruturalismo na matemática e a abordagem piagetiana a este estruturalismo, bem como uma história da constituição e desenvolvimento do MMM, sejam apresentados de modo breve, mas adequado em seu detalhamento, de modo a conduzir o leitor para a discussão sobre a geometria nesses tempos de modernização do ensino.

Dos livros didáticos para o ensino primário destacam-se aqueles produzidos por Anna Franchi, Lucília Bechara Sanchez e Manhúcia Perelberg Liberman ${ }^{7}$, “verdadeiros best-sellers do ponto de vista da quantidade de exemplares vendidos ao tempo do MMM". Sintetizando, os autores desse capítulo afirmam que "numa análise breve, pode-se dizer que, pelo menos em termos das normas para o trabalho pedagógico, altera-se substancialmente a organização dos conteúdos escolares matemáticos a serem ensinados para as crianças. Ainda que os dois primeiros livros desse Curso Moderno de Franchi, Sanchez e Liberman não abordem - ou tratem de forma brevíssima, como no caso do segundo volume - o tema geometria, o terceiro volume, no seu item Noções de Geometria, inaugura “o estudo de conceitos topológicos como dentro, fora, aberto e fechado, regiões, que se caracterizam como inovadores para o ensino

\footnotetext{
${ }^{7}$ Trata-se da coleção Curso moderno de matemática para a escola elementar, cujo primeiro dos cinco volumes foi lançado entre 1966 e 1967 (as edições publicadas quando já em vigor a lei 5692 têm o título alterado para Curso moderno de matemática para o ensino de $1^{\circ}$. grau, atendendo à nova nomenclatura da seriação escolar, imposta a partir de 1971). Um dentre os tantos diferenciais que tornam emblemática essa coleção é a formação das autoras: "a elaboração de obras didáticas para o ensino das primeiras letras, em especial aquelas de matemática, até meados da década de 1960, não tem autoria de professores formados em cursos de licenciatura em matemática. Liberman, Franchi e Bechara têm essa formação".
} 
primário. [...] [e] pode-se dizer que a articulação entre os conceitos topológicos e a geometria euclidiana se dá por meio da linguagem dos conjuntos”.

A disposição em incluir temas da topologia - ou apostar numa abordagem topológica em detrimento da perspectiva euclidiana, apenas -, que serviria para outras coleções e livros do mesmo período, radica-se na proposta fundamentadora do MMM, estruturalista (e) piagetiana $^{8}$, cuja ênfase foi marcada por três eixos matemáticos que guiariam a forma dos programas escolares e suas diretrizes psicopedagógicas: as estruturas algébricas, as noções topológicas e a relação de ordem.

A cultura escolar estabelecida, com seus valores, concepções e estratégias arraigados, entretanto, subverte homeopaticamente essas disposições revolucionárias, e acentua, mesmo nesses tempos de modernização - que não demorarão muito para se exaurir -, a abordagem euclidiana: trata-se, aqui, de outro exemplo de como as alterações e manutenções - cerne dos estudos historiográficos, reitero - ocorrem no universo da escola:

\begin{abstract}
Mesmo em meio a um contexto revolucionário de propostas de mudança da matemática escolar, [sintetizam os autores], o MMM encontrou o cotidiano pronto para incorporar novos elementos da geometria sem que efetivamente tenha sido abandonada a referência da geometria euclidiana. Por entre as páginas e páginas dos livros didáticos que enfatizavam os elementos da teoria dos conjuntos, logo viria a geometria com os primeiros itens da topologia. Mas esses elementos mesclaram-se, servindo como rápida introdução para o estudo das figuras geométricas [numa abordagem] euclidiana (PINTO; VALENTE in SILVA; VALENTE, 2014, p. 81-2).
\end{abstract}

A experiência dos autores sobre o MMM e o ensino de determinados conteúdos matemáticos na órbita desse movimento, já o dissemos, permite que temas muito diversificados sejam abordados de forma sintética, mas correta e adequada para permitir um encadeamento de ideias que, em consequência, retrata, em sua dinâmica de alterações e manutenções, o ensino de geometria no ensino primário brasileiro nas cercanias dos anos de 1960. Essa mesma experiência, porém, pode justificar o que eu percebo como sendo um certo afastamento em relação ao leitor que se tem em mente para o livro: o professor que ensina matemática.

Dos três capítulos até aqui analisados, este, o terceiro, é o que mais se aproxima de uma abordagem acadêmica - seja em sua forma, seja no modo de tratar a literatura que surge como apoio às ideias apresentadas ou, ainda, no que diz respeito aos conteúdos (ou, mais propriamente, à abordagem proposta para os conteúdos) tratados na escola sob a égide do

\footnotetext{
${ }^{8}$ De acordo com Inhelder e Piaget, segundo os autores deste capítulo, “a criança passa primeiro pelo estágio topológico, antes do euclidiano, na apropriação do espaço. /.../ Dever-se-ia [então] abandonar a milenar ideia do ensino dos rudimentos dos elementos de Euclides, voltando-se a atenção para os elementos de topologia”.
} 
MMM. Essa opção pelo tom - mais acadêmico que o dos dois primeiros $\operatorname{capítulos}^{9}$ - não é, sob meu ponto de vista, tão problemática para o público-alvo posto que, embora mais cifrada em seus conceitos, a elaboração textual é sempre clara. Entretanto, a alusão demasiado frequente a conceitos aparentemente desconhecidos (ou, pelo menos, mais distantes) dos professores que ensinam matemática é, sim, problemática. Notemos, por exemplo, o uso reiterado do termo topologia e suas variações (estruturas topológicas, estágio topológico, conceitos topológicos, distinção entre geometria euclidiana e topologia etc) ${ }^{10}$. Sabe-se que o professor que ensina matemática não necessariamente passou pelos bancos escolares em cursos de Licenciatura em Matemática, e mesmo aos licenciandos em Matemática, na quase totalidade dos cursos atualmente vigentes no país, não é oferecida a disciplina Topologia, nem sua introdução mais óbvia na cadeia dos conteúdos matemáticos sistematizados, o tratamento dos espaços métricos. Sem esse feedback, esses leitores potenciais dificilmente darão conta de, com esse capítulo, entender o que subjaz à proposta do MMM e, em decorrência, terão dificuldade de identificar, no tratamento dos livros da época, por exemplo, a diferenciação ou aproximação subversora entre euclidiano e topológico. A experiência dos autores, obviamente, permitiria tratar com mais detalhamento esses termos e expressões aparentemente delicados sem comprometer o fluxo do texto. Poder-se-ia, talvez, sugerir ao leitor-alvo, de forma mais incisiva, leituras complementares ou, ainda, incorporar ao livro um apêndice com uma série de verbetes (ao modo de um pequeno glossário) que serviria de guia básico para esses leitores. Ficam, aqui, essas sugestões para as edições futuras que, certamente, serão produzidas.

O último e o mais longo dos quatro capítulos do livro, de autoria de Paulo Figueiredo Lima e João Bosco Pitombeira de Carvalho, é, segundo minha perspectiva, oposto, em seu tom, ao capítulo anterior. Seu subtítulo, Conversas com o professor que ensina matemática, anuncia, exatamente, o que o leitor encontrará nele: um diálogo muito cuidadoso com os professores sobre os conteúdos e os modos de trabalhar esses conteúdos nas salas de aula do

\footnotetext{
${ }^{9}$ Notemos que os dois primeiros capítulos, ainda que não tenham um "tom acadêmico", valendo-se, ao contrário, de uma linguagem e de um modo de mobilização de conceitos mais próximos à linguagem usual - conseguem prender tanto a atenção do especialista quanto do leigo interessado nos temas neles apresentados, sem que haja concessões quanto à profundidade, pertinência ou correção das ideias discutidas, ainda que alguns elementos mais propriamente teóricos - digamos assim -, reconhecíveis à comunidade de pesquisadores, mas estranhos ou não usuais a outras comunidades, fiquem necessariamente subjacentes, dada a opção por um determinado público-alvo.

${ }^{10}$ A mesma consideração se aplica para outros termos, próprios da linguagem matemática, como Estruturas Algébricas e ordem, por exemplo, mas obviamente não se aplicam a termos como conjuntos, ângulos, retas perpendiculares etc, que frequentam a escolarização em todos os níveis, enquanto aqueles, quando muito, frequentam apenas os cursos superiores de Matemática, sendo, entretanto, mais essenciais para entender a proposta do MMM, tema do capítulo.
} 
ensino inicial. Os temas abordados são bastante variados: a ideia de dimensão em geometria, as representações gráficas, as projeções, as perspectivas e a classificação das figuras geométricas. O tratamento é rigoroso, mas não formalizado a ponto de afastar o leitor não muito familiarizado com a matemática. Ao contrário, o capítulo foi elaborado ao modo de um guia que pode auxiliar professores, futuros professores e até mesmo autores de livros didáticos em suas dúvidas ou intenções de produzir materiais ou discutir temas relativos ao ensino de geometria. A experiência de ambos os autores desse capítulo não só quanto à pesquisa em Matemática ou em Educação Matemática e - talvez mais decisivamente - a vinculação de ambos à avaliação de livros didáticos de matemática brasileiros, no Programa Nacional do Livro Didático (PNLD), resultam num texto cujo viés é mais de natureza didática que propriamente historiográfica: o capítulo ensina e esclarece alguns elementos básicos de geometria que constam dos atuais programas de ensino para a escolaridade inicial, e faz isso de forma muito clara. Assim, ainda que destoe dos demais capítulos em sua natureza, dialoga com eles em sua intenção de ter como interlocutor o professor que ensina matemática.

A conclusão dessa sequência de esforços para compreender o ensino de geometria e as dinâmicas de transformação desse saber escolar ao longo do tempo sintetiza alguns ingredientes fundamentais discutidos no livro, e enuncia, de forma clara, aquilo que penso ser uma das maiores contribuições do estudo. Trata-se de uma caracterização do fazer do professor que ensina matemática que, embora já tenha sido referenciada por Kaleff em sua apresentação ao texto, nesse momento, nas conclusões, ganha densidade por surgir como resultado da série de construções argumentativas que ocuparam todo o volume: a geometria escolar constitui-se num percurso pleno de contraposições e incorporações no qual foram elaborados e reelaborados ingredientes didático-pedagógicos que a constituem num saber transitório que faculta o acesso ao saber sistematizado da geometria, à geometria da matemática. Essa caracterização da geometria escolar, por sua vez, permite que se compreenda "que o professor que ensina matemática não é um especialista em matemática; sua especialidade liga-se à condução dos alunos a progressivamente apropriarem-se de uma cultura transitória que dá acesso aos saberes científicos”. Essa conclusão, embora não decorra apenas dos estudos historiográficos acerca do ensino de matemática que encontramos nessa coletânea organizada por Silva e Valente, pode apoiar-se de forma inequívoca nesses estudos, o que torna esse livro uma contribuição preciosa não só para professores que ensinam matemática ou professores em formação (que ensinarão matemática), mas aos interessados em História da Educação Matemática e aos pesquisadores que, mantendo ou não uma 
aproximação com a historiografia, dedicam-se ao estudo da formação e da atuação docente no Brasil.

\section{Referências}

CARVAlHO, J. M. de. A formação das almas: o imaginário da república no Brasil. São Paulo: Companhia das Letras, 2006.

CONDORCET. Cinco Memórias sobre a instrução pública. São Paulo: Editora UNESP, 2008.

GOMES, M. L. M. Quatro visões iluministas sobre a educação matemática. Campinas: Editora UNICAMP, 2008.

LACROIX, S. F. Ensaios sobre o ensino em geral e o de matemática em particular. São Paulo: Editora UNESP, 2013.

LIMA, P. F.; CARVALHO, J. B. P. de . A Geometria Escolar hoje: conversas com o professor que ensina matemáticas In: SILVA, M. C. L. da; VALENTE, W. R. (Org.). A geometria nos primeiros anos escolares: história e perspectivas atuais. Campinas: Papirus, 2014. p. 83-128.

MONTOITO, R. Euclid and his modern rivals (1879), de Lewis Carroll: tradução e crítica. 2013. Tese (Doutorado em Ensino de Ciências e Matemática) - Programa de Pós-graduação em Educação para a Ciência, Faculdade de Ciências, UNESP, Bauru, 2013.

MONTOITO, R.; GARNICA, A. V. M. Ecos de Euclides: notas sobre a influência d'Os Elementos a partir de algumas doutrinas filosóficas. Educação Matemática Pesquisa. São Paulo, v. 16, n. 1, p. 95123, 2014.

PINTO, N.B.; VALENTE, W.R.. Quando a Geomeria tornou-se moderna: tempos do MMM. In: SILVA, M. C. L. da; VALENTE, W. R. (Org.). A geometria nos primeiros anos escolares: história e perspectivas atuais. Campinas: Papirus, 2014. p. 65-82.

SILVA. M.C.L. da; VALENTE, W.R. A Geometria nos Grupos Escolares. In: SILVA, M. C. L. da; VALENTE, W. R. (Org.). A geometria nos primeiros anos escolares: história e perspectivas atuais. Campinas: Papirus, 2014. p. 41-64.

VALENTE, W.R.; SILVA, M.C.L. da. Primórdios do Ensino de Geometria nos Anos Iniciais. In: SILVA, M. C. L. da; VALENTE, W. R. (Org.). A geometria nos primeiros anos escolares: história e perspectivas atuais. Campinas: Papirus, 2014. p. 17-40. 